\title{
Does adjuvant steroid therapy post-Kasai portoenterostomy improve the outcome of biliary atresia? A systematic review and meta-analysis
}

\author{
Ahmed Sarkhy MBBS MHSC FAAP FRCPC ${ }^{1}$, Richard A Schreiber MDCM FRCPC ${ }^{2,3}$, \\ Ruth Milner $\mathrm{MSC}^{4}$, Collin C Barker MD FRCPC ${ }^{2,3}$
}

\begin{abstract}
A Sarkhy, RA Schreiber, R Milner, CC Barker. Does adjuvant steroid therapy post-Kasai portoenterostomy improve the outcome of biliary atresia? A systematic review and metaanalysis. Can J Gastroenterol 2011;25(8):440-444.

BACKGROUND: The role of adjuvant steroid therapy in the postoperative management of patients with biliary atresia (BA) is unclear. OBJECTIVE: To systematically review the literature and perform a meta-analysis to determine the efficacy of adjuvant steroid therapy post-Kasai portoenterostomy (KP) on BA outcome.

METHODS: A systematic review and meta-analysis of randomized trials and/or observational studies that examined the role of steroids on BA outcomes published between January 1969 and June 2010 was conducted. Studies were identified using the Medline, PubMed, EMBASE and Cochrane databases.

RESULTS: Sixteen observational studies and one randomized controlled trial (RCT) were found. Four of the 16 observational studies (160 participants) and the RCT (73 participants) met the entry criteria and were eligible to be included in the analysis. There was no statistically significant difference in the effect of steroids either on normalizing serum bilirubin levels at six months (pooled OR 1.48 [95\% CI 0.67 to 3.28]) or in delaying the need for early liver transplantation (within the first year post-KP (pooled OR 0.59 [95\% CI 0.21 to 1.72]).

CONCLUSION: The present meta-analysis did not find a significant effect of steroid over standard therapy, either in normalizing serum bilirubin levels at six months or at delaying the need for early liver transplantation post-KP. RCT studies of sufficient size and comprehensive design using high-dose steroids are needed to determine the effectiveness of steroids on the short and intermediate post-KP outcomes for BA patients.
\end{abstract}

Key Words: Biliary atresia; Corticosteroids; Kasai portoenterostomy; Liver transplantation; Systematic review

$\mathbf{Q}$ iliary atresia (BA) is a uniquely pediatric liver disease characterBized by an idiopathic, progressive fibrosclerosing obliteration of the large extra- and intrahepatic bile ducts that results in chronic cholestasis, biliary cirrhosis and end-stage liver disease in children (1). While the precise etiology and pathogenesis of BA are largely unknown, several patient and animal studies support the theory that BA is an immune-mediated disease predominantly involving the $\mathrm{T}$ helper cell 1 proinflammatory cascade (2). BA is a rare disorder, with a varying incidence among different populations ranging from one in 5500 in Asians, to one in 19,000 in Caucasians (1). However, it is the most prevalent cause of liver-related death in children and the most frequent indication for liver transplantation (LT) in the pediatric population (3). The condition manifests exclusively in the neonatal period with jaundice and acholic stools. At least two clinical phenotypes have been recognized. (4).

\section{Une stéroïdothérapie adjuvante après une porto- entérostomie de Kasai améliore-t-elle l'issue de l'atrésie biliaire? Une analyse systématique et une méta-analyse}

HISTORIQUE : On connaît mal le rôle de la stéroïdothérapie adjuvante dans la prise en charge postopératoire des patients atteints d'atrésie biliaire $(A B)$.

OBJECTIF : Procéder à une analyse systématique et effectuer une méta-analyse pour déterminer l'efficacité d'une stéroïdothérapie adjuvante après une porto-entérostomie de Kasai $(\mathrm{PK})$ sur l'issue de l'AB. MÉTHODOLOGIE : Les chercheurs ont effectué une analyse systématique et une méta-analyse d'essais aléatoires ou d'études d'observation qui traitaient du rôle des stéroïdes sur les issues de l'AB entre janvier 1969 et juin 2010. Ils ont repéré les études grâce aux bases de données Medline, PubMed, EMBASE et Cochrane.

RÉSULTATS : Les chercheurs ont retracé 16 études d'observation et un essai aléatoire et contrôlé (EAC). Quatre des 16 études d'observation (160 participants) et l'EAC (73 participants) respectaient les critères d'inclusion et étaient admissibles à l'analyse. Il n'y avait pas de différence statistiquement significative quant à l'effet des stéroïdes, que ce soit pour normaliser les taux de bilirubine sérique à six mois (RRR groupé 1,48 [95\% IC 0,67 à 3,28]) ou pour reporter la nécessité d'une greffe hépatique précoce (dans la première année suivant la PK; RRR groupé 0,59 [95 \% IC 0,21 à 1,72]).

CONCLUSION : La présente méta-analyse n'a pas établi que les stéroïdes avaient des effets significatifs par rapport à la thérapie standard, que ce soit pour normaliser les taux de bilirubine sérique à six mois ou pour retarder la nécessité d'une greffe hépatique précoce après une AP. Des EAC d'une dimension suffisante et à la méthodologie détaillée, faisant appel à de fortes doses de stéroïdes, s'imposent pour déterminer l'efficacité des stéroïdes sur les issues à court et à moyen terme après une PK chez les patients ayant une AB.

The current standard of care for BA, regardless of phenotype, is sequential surgical management with an initial Kasai portoenterostomy $(\mathrm{KP})$, in which the obstructed extrahepatic bile ducts are resected and a loop of bowel is brought to the porta of the liver in an effort to reestablish bile flow, followed by LT for cases that progress to liver failure. Infants who do not undergo initial KP require semi-urgent LT for survival and have a poorer prognosis. Left untreated, all infants with BA die by three years of age (3).

The long-term survival of BA patients with their native liver, without requiring LT, depends largely on the success of the initial KP. A successful KP restores biliary flow, results in normalization of serum bilirubin levels (SBL) and obviates the need for early LT. Conversely, in those with a failed KP, survival requires LT in early infancy at a time when patient age and growth are immutable risk factors for wait-list mortality and poor LT outcome.

\footnotetext{
${ }^{1}$ Division of Gastroenterology, Department of Pediatrics, King Khalid University Hospital, King Saud University, Riyadh, Saudi Arabia; ${ }^{2}$ Division of

Gastroenterology, Hepatology and Nutrition; ${ }^{3}$ Department of Pediatrics; ${ }^{4}$ Department of Surgery, BC Children's Hospital, University of British

Columbia, Vancouver, British Columbia

Correspondence: Dr Richard A Schreiber, Division of Gastroenterology, Room K4-200, BC Children's Hospital, 4480 Oak Street, Vancouver,

British Columbia V6H 3V4. Telephone 604-875-2332 ext 1, fax 604-875-3244, e-mail rschreiber@cw.bc.ca

Received for publication December 1, 2010. Accepted January 15, 2011
} 
The success of the initial KP depends on several factors, of which patient age at the time of the procedure is the most important determinant - the older the infant age at the time of surgery, the less successful the outcome and the less favourable is the post-KP native liver survival. In particular, infants older than 90 days of age at the time of surgery have worse outcomes $(5,6)$. Recent European studies (7) have suggested that case-load experience and the expertise of the site and surgeon may also influence the outcome of KP; however, the case volumes and extent of site experience needed to achieve outcome advantage remain uncertain. Other strategies to improve post-KP native liver survival, mostly directed toward postoperative patient care management, include the use of prophylactic antibiotics to prevent recurrent cholangitis, the addition of choleretic agents such as ursodeoxycholic acid to stimulate bile flow and the initiation of aggressive nutritional support to enhance growth (8). Whether corticosteroids, because of their putative anti-inflammatory, immunomodulatory and choleretic properties, further improve the outcome for BA patients post-KP remains controversial despite the many observational studies over the past several decades (9-24). The aim of the present study was to systematically review the literature and, using a metaanalysis, determine the efficacy of adjuvant postoperative steroid therapy on the outcome of KP in patients with BA.

\section{METHODS}

Study selection

Articles in four databases (MEDLINE, PubMed, EMBASE and the Cochrane database) published between January 1969 and June 2010 were searched systematically by two independent reviewers. The search was limited to the English language literature and human studies, and included both observational studies and randomized controlled trials (RCTs). First, MeSH terms and text words including biliary atresia, bile ducts, hepatoportoenterostomy/portoenterostomy, and Kasai procedure, were entered. Second, the search was extended by using the MeSH terms and the text words steroids, corticosteroids, dexamethasone, methyl/prednisolone and hydrocortisone. The two searches were subsequently combined. Relevant articles were retrieved based on consensus among authors. Finally, the reference lists of the retrieved articles were searched for other potentially relevant articles.

\section{Data extraction}

Only studies that compared two groups (steroid therapy versus standard therapy) of infants who underwent KP surgery were selected. Studies were required to present data pertaining to RR or ORs, or at least, had to present sufficient data to allow these estimates to be calculated. Outcomes of interest included normalization of SBL at six months post$\mathrm{KP}$ and early LT (defined as the need for LT within the first year post$\mathrm{KP}$ ). Data regarding study design, sample size, participant characteristics, steroids doses, forms and routes of administration, time of start and duration of therapy were extracted. Studies with an inconsistent steroid therapy protocol (ie, using different steroids doses or types in the same study), or those that did not report the outcomes of interest, or did not report sufficient data to calculate RR or ORs were excluded. Studies that reported duplicated results were also excluded. Steroid use was defined as use of any type of steroids at any time after KP. The methodological quality of nonrandomized studies was assessed using the Newcastle-Ottawa Scale (25). Studies with a low risk of bias were scored as ' $\mathrm{A}$ ' (7 to 9 points), studies with a moderate risk for bias were scored as 'B' ( 4 to 6 points) and studies with a high risk of bias were scored as ' $\mathrm{C}$ ' ( 1 to 3 points). The Jadad score was used to assess RCTs (26). All studies were reviewed by two of the authors (AS, CB) and discrepancies were resolved by consensus.

\section{Data analysis}

A random-effects model was used to calculate the pooled OR and 95\% CIs because this particular type of model represents a more conservative approach (27). Due to the rarity of BA, it was assumed that an OR from a case-control study approximated the RR in a cohort study. Cohort studies were statistically combined with case-control studies for meta-analysis in the absence of significant statistical heterogeneity.

Because tests of heterogeneity may be underpowered to detect heterogeneity among studies when the number of studies is small, heterogeneity was also explored graphically and quantitatively using the $\mathrm{I}^{2}$ statistic. An I2 statistic of less than $25 \%$ was considered to represent good homogeneity, while an $\mathrm{I}^{2}$ of $25 \%$ to $50 \%$ was considered to have reasonable homogeneity. An $\mathrm{I}^{2}$ statistic of greater than $50 \%$, however, was considered to represent significant heterogeneity between studies and, on this basis, it was decided not to statistically combine their results.

Sensitivity analysis was performed to investigate the effect of highdose steroids $(10 \mathrm{mg} / \mathrm{kg})$ versus low $/$ medium-dose steroids on the outcomes of interest, and to determine whether a dose-response effect was present. Meta-analysis was performed using RevMan version 5 (RevMan, Denmark).

\section{RESULTS}

The search yielded 16 observational studies (9-24) and one RCT (28). Of these, four observational studies with total number of 160 participants (111 patients in three case-control studies, and 49 patients in one cohort study) and a single RCT with 73 participants satisfied the inclusion criteria (Table 1). In general, the mean age at surgery was three months or younger in the selected studies. There were no significant differences in SBL before surgery among the study cohorts in each of the selected studies apart from the study by Chung et al (23), in which mean $( \pm$ SD) SBL were mildly higher in the control $(160.2 \pm 18.3 \mu \mathrm{mol} / \mathrm{L})$ versus the steroid group $(146.2 \pm 14.2 \mu \mathrm{mol} / \mathrm{L})$. Apart from the study by Chung et al (23), in which a single surgeon performed the surgery, the procedure was performed by at least two surgeons in all other studies. The introduction of postoperative adjuvant therapies including intravenous antibiotics, choleretic agents and nutritional support, as well as their treatment duration, were not uniform among the included studies (Table 1). Twelve studies were excluded for any of three major reasons: no control group; no single standardized steroid therapy protocol for all patients; or the outcomes of interest were not measured (Table 2).

\section{Assessment of the methodological quality of the included studies}

Two investigators independently rated the methodological quality of the selected studies using the Newcastle-Ottawa Scale for observational studies. Apart from the study by Meyers et al (12), which graded moderate risk of bias ' $B$ ', all of the included observational studies were graded ' $\mathrm{A}$ ', corresponding to a low risk of bias. The single RCT, reported by Davenport et al (28), used the Jadad score to assess controlled trials, and was scored 3 (out of a possible 5) because it did not include a detailed description of the randomization and blinding processes (Appendix 1).

\section{Effect of steroids on SBL at six months postsurgery}

Using the random-effects model, there was no significant difference in the effect of steroids on normalizing SBL at six months (OR 1.48 [95\% CI 0.67 to 3.28]; $\mathrm{P}=0.09$ for heterogeneity; $\mathrm{I}^{2}=50 \%$ ) (Figure 1). Although Meyers et al (12) reported normalization of SBL at three to four months, rather than at six months, the study was included in the meta-analysis because it was expected that all patients experiencing a normalization of SBL by four months would be considered to have a functioning $\mathrm{KP}$ from then through to six months.

Effect of steroids on early LT (within the first year of the surgery) The meta-analysis of the effect of steroids on early LT suggested some effect in delaying early LT; however, it was not statistically significant (OR 0.59 [95\% CI 0.21 to 1.72 ]; $\mathrm{P}=0.17$ for heterogeneity; $\mathrm{I}^{2}=43 \%$ ) (Figure 2). The study by Petersen et al (22) was excluded from the meta-analysis of this outcome because they reported on the need for LT at two years rather than at one year. 
TABLE 1

Summary of the pre- and postoperative characteristics of the included studies

\begin{tabular}{|c|c|c|c|c|c|}
\hline & \multicolumn{5}{|c|}{ Author (reference), year, country } \\
\hline & $\begin{array}{c}\text { Petersen et al (22), 2008, } \\
\text { Germany }\end{array}$ & $\begin{array}{c}\text { Meyers et al (12), 2003, } \\
\text { United States }\end{array}$ & $\begin{array}{l}\text { Vejchapipat et al (18), } \\
\text { 2007, Thailand }\end{array}$ & $\begin{array}{c}\text { Chung et al (23), 2008, } \\
\text { Hong Kong }\end{array}$ & $\begin{array}{c}\text { Davenport et al (28), 2007, } \\
\text { United Kingdom }\end{array}$ \\
\hline Study design & Cohort & Case control & Case control & Case control & $\begin{array}{l}\text { Randomized control } \\
\text { ( } 2 \text { centres })\end{array}$ \\
\hline Sample size, $\mathrm{n}$ & 49 & 28 & 53 & 30 & 73 \\
\hline Steroid treatment, $\mathrm{n}$ & 20 & 14 & 33 & 13 & 36 \\
\hline Standard treatment, $\mathrm{n}$ & 29 & 14 & 20 & 17 & 37 \\
\hline Steroid treatment & $63 \pm 32$ & $<84$ & $84.7 \pm 25.7$ & $69.7 \pm 12.3$ & 60 (range $50-71$ ) \\
\hline Standard treatment & $57 \pm 22$ & $\begin{array}{c}<84(\mathrm{n}=12) ; 91(\mathrm{n}=1) \\
112(\mathrm{n}=1)\end{array}$ & $98.3 \pm 38$ & $62.5 \pm 16.5$ & 54 (range $45-70$ ) \\
\hline \multicolumn{6}{|l|}{ Mean SBL at KP, $\mu \mathrm{mol} / \mathrm{L}$} \\
\hline Steroid treatment & $175 \pm 67$ & 153.9 & $189.8 \pm 44.5$ & $146.2 \pm 14.2$ & 132 (range $112-166$ ) \\
\hline Standard treatment & $165 \pm 60$ & 136.5 & $176.13 \pm 49.6$ & $160.2 \pm 18.3$ & 158 (range $125-183$ ) \\
\hline $\begin{array}{l}\text { Other adjuvant } \\
\text { therapies }\end{array}$ & $\begin{array}{l}\text { Antibiotics, Urso, fat- } \\
\text { soluble vitamins, МСТ }\end{array}$ & Antibiotics, Urso & $\begin{array}{l}\text { Antibiotics, Urso, } \\
\text { fat-soluble vitamins }\end{array}$ & Not stated & $\begin{array}{l}\text { Antibiotics, Pheno, } \\
\text { fat-soluble vitamins, MCT }\end{array}$ \\
\hline
\end{tabular}

bid Twice/day; IV Intravenous; KP Kasai portoenterostomy; MCT Medium chain triglyceride formula; MP Methylprednisolone; Pheno Phenobarbital; SBL Serum bilirubin level; Urso Ursodeoxycholic acid

TABLE 2

\section{Summary of the excluded studies}

\begin{tabular}{ll}
\hline Author (reference) & Reason for exclusion \\
\hline Dillon et al (11), Muraji et al (13), & No control group \\
Shimadera et al (17), & \\
Foroutan et al (20) &
\end{tabular}

Escobar et al (16) Inconsistent steroid protocol

Karrer and Lilly (9), Muraji et al (13), Did not measure the outcome of interest Kobayashi et al (14), Tatekawa or did not present sufficient data to et al (15), Stringer et al (19), calculate RR or OR

Shimadera et al (17)*,

Lao et al (24)

*Shimadera et al published two articles $(17,21)$, both were excluded because they did not have a control group and did not measure the outcome of interest. The study by Muraji et al (13) was excluded to avoid duplication of results because it was a nationwide survey that collected data from other centres in Japan

Sensitivity analysis

A sensitivity analysis was performed to examine the effect of steroid dose and the dose-response relationship. Although the studies by Meyers et al (12) and Petersen et al (22) both used high-dose steroid doses $(10 \mathrm{mg} / \mathrm{kg})$, the significant heterogeneity between them did not permit calculation of a pooled OR and $95 \% \mathrm{CI}$.

\section{Publication bias}

Initially, funnel plots to assess publication bias were planned; however, due to the small number of selected studies, it was inappropriate to assess for publication bias using this method. It has been previously shown that five or fewer studies is insuffient to detect funnel plot asymmetry (29).

\section{DISCUSSION}

The theory that adjuvant steroid therapy might improve on the success of $\mathrm{KP}$ and post-KP native liver survival has persisted in the medical

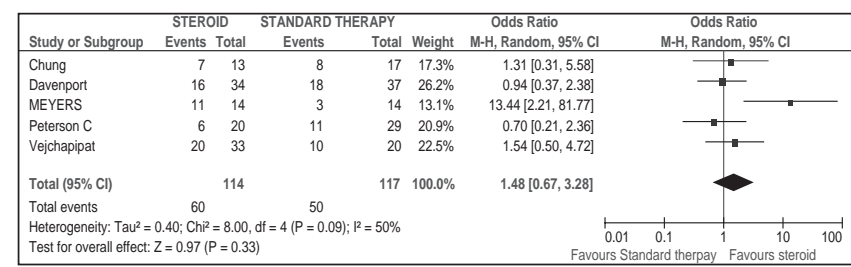

Figure 1) Effect of steroid on normalizing serum bilirubin level at six months post-Kasai portoenterostomy. Events refer to the number of patients with normal serum bilirubin levels at six months post-Kasai portoenterostomy out of the total number of patients in each respective therapy group

\begin{tabular}{|c|c|c|c|c|c|c|c|c|}
\hline Study or Subgroup & \multicolumn{2}{|c|}{ Steroid therapy } & \multicolumn{2}{|c|}{ Standard therapy } & Weight & $\begin{array}{c}\text { Odds Ratio } \\
\text { M-H, Random, } 95 \% \mathrm{Cl}\end{array}$ & \multicolumn{2}{|c|}{$\begin{array}{c}\text { Odds Ratio } \\
\text { M-H, Random, } 95 \% \mathrm{CI}\end{array}$} \\
\hline Chung et al 2008 & 5 & 13 & 5 & 17 & $29.5 \%$ & $1.50[0.33,6.92]$ & & $\pi$ \\
\hline Davenport tet al 2007 & 9 & 34 & 13 & & $44.7 \%$ & $0.66[0.24,1.84]$ & $=$ & \\
\hline Meyers et al 2003 & 3 & 14 & 8 & 13 & $25.8 \%$ & $0.17[0.03,0.93]$ & & \\
\hline Total $(95 \%$ CI) & & 61 & & & $100.0 \%$ & $0.59[0.21,1.72]$ & & \\
\hline \multirow{2}{*}{\multicolumn{7}{|c|}{$\begin{array}{l}\text { Total events } \quad 17 \quad 26 \\
\text { Heterogeneity: } \text { Tau }^{2}=0.39 ; \mathrm{Ch}^{2}=3.53 \text {, df }=2(\mathrm{P}=0.17) ; 1^{2}=43 \% \\
\text { Test for overall effect } Z=0.96(\mathrm{P}=0.34)\end{array}$}} & & \\
\hline & & & & & & & \begin{tabular}{lc|}
0.01 & 1 \\
Favours standard therapy
\end{tabular} & \begin{tabular}{|l|l|}
1 & 1 \\
1 & 100 \\
Favours steroid therapy
\end{tabular} \\
\hline
\end{tabular}

Figure 2) Effect of steroids on early liver transplantation (within the first year post-Kasai portoenterostomy). Events refer to the number of patients who underwent early liver transplantation within the first year of Kasai portoenterostomy out of the total number of patients in each respective therapy group

literature ever since the procedure was first described in the Japanese literature in 1959 (30), and later accepted as standard therapy for BA in the western world in 1976. Indeed, recent reports from the Japanese BA registry (13) confirm that almost all Japanese children with BA now receive steroid therapy routinely as part of their postoperative treatment protocol. A recent study conducted in the United States (US) (24) found that almost one-half of the BA patients managed at Pediatric Health Information System hospitals are given postoperative steroids. However, there is a paucity of evidence to support steroid therapy as standard postoperative treatment for BA infants. 
In the present study's review of the world literature from 1969 to 2010, a total of 17 studies that reported on the use of steroids in patients with BA were identified. Five studies, including three case control, one cohort and one RCT, were acceptable for our metaanalysis because they incorporated comparison groups, permitted estimates of RR or ORs, and included relevant outcomes of interest. The majority of the remaining 12 observational studies were excluded from our meta-analysis because they lacked a comparative control group or did not provide sufficient data to calculate an RR or OR. Since the first report by Karrer and Lilly (9) in 1985, the only randomized controlled steroid trial (28) proved to be a negative study.

Our study was the first to apply a systematic review with metaanalysis to examine the effect of steroids on post-KP outcome. We did not find a statistically significant effect of adjuvant steroid therapy compared with standard therapy on the normalization of SBL within six months post-KP surgery, or the need for early LT within the first year of the surgery.

It has long been recognized that SBL post-KP surgery is an important predictor - at least in the short term - for the outcome of BA. Normalization of SBL in BA patients is an indirect biomarker reflecting the successful re-establishment of bile flow following surgical KP and predicts a good outcome for native liver survival. In the pretransplant era, a successful KP was associated with a five-year native liver survival rate of $50 \%$ to $100 \%$. A recent European study that examined early predictors of success of KP (31) found that BA patients with SBL of lower than $57 \mu \mathrm{mol} / \mathrm{L}$ six weeks after $\mathrm{KP}$ had a five-year native liver survival rate of $100 \%$. The US multicentre Biliary Atresia Research Consortium (BARC) study (32) reported that children with normal SBL by three months post-KP had an $84 \%$ native liver survival rate at approximately two years post-KP. In contrast, patients experiencing persistent jaundice in association with marked elevation in SBL post$\mathrm{KP}$, reflecting a failure of restoration of the bile flow, had a poorer prognosis (33). Of the 125 infants who underwent $\mathrm{KP}$ in the comprehensive report by Lilly et al (33) (conducted during the pretransplant era), the three-year survival rate of patients whose jaundice failed to clear after the operation was $6.7 \%$. In the more recent BARC National Institutes of Health-sponsored study (32), the two-year native liver survival rate without LT was only $16 \%$ in the cohort with SBL of greater than $102 \mu \mathrm{mol} / \mathrm{L}$ at three months post-KP - significantly lower than infants who had normalized SBL.

Undergoing successful KP with sustained clearance of jaundice obviates the need for early LT. As such, the outcome measures used in the present meta-analysis - the normalization of SBL at six months or the need for LT within one year post-KP - are effectively similar because they both reflect the early phase success of $\mathrm{KP}$ in re-establishing bile flow, which in turn, will influence SBL and the medium- to more longterm survival of patients with their native liver. It is not surprising, therefore, that in any individual study, we did not find variance in the effect of steroids on these two outcome determinants.

There was a considerable degree of heterogeneity among the included studies that could be attributed to differences in the mean ages at $\mathrm{KP}$, doses and duration of steroid therapy, as well as inconsistent use of other adjuvant therapies such as antibiotics, choleretic agents and nutritional support.

Limiting the analysis to include only the two studies that used a highdose steroid regimen $(10 \mathrm{mg} / \mathrm{kg})$, postsurgery $(12,22)$ was not possible because of the significant heterogeneity between them and the consequent inability to proceed with statistical combination of their results. Interestingly, the results of the two high-dose steroid trials were opposite, with a beneficial effect of steroids found in one (12) and no improvement reported in the other (22), possibly related to the differences in the range of ages of the patients at KP between the two studies.

The single RCT reported by Davenport et al (28) was a negative study; however, the lack of a significantly favourable steroid outcome may have been the result of the small study sample size, which did not have sufficient power to detect a difference between the steroid treatment and placebo groups. Moreover, the study design used a low-to medium-dose steroid ( $2 \mathrm{mg} / \mathrm{kg}$ ) for a short period (four weeks) as opposed to many other observational studies that used higher doses ( $10 \mathrm{mg} / \mathrm{kg}$ or more) for longer periods (up to 12 weeks). Furthermore, the study design called for the administration of steroid treatment to start one week after the KP operation. The large prospective placebo controlled trial currently recruiting in the US (34) may overcome many of these issues, although this particular study is designed for treatment induction with an intermediate dose of intravenous methylprednisolone $(4 \mathrm{mg} / \mathrm{kg})$ commencing one to three days post-KP.

The study by Meyers et al (12) was the only study included in our analysis that found a statistical difference in favour of steroids between the two study cohorts. This study contained the numerically smallest groups with the lowest weight and, in our quality assessment, was scored as having a moderate risk of bias compared with the other included studies, which may explain its significantly different results.

We acknowledge that our systematic review is not without limitations. The observational nature of most of the included studies makes them prone to selection and performance bias. Although we tried to minimize these effects by restricting the eligibility criteria for study inclusion, the influence of these confounding factors on the selected studies cannot be ignored or eliminated. For example, in most of these studies, patient selection to steroid-treated or placebo groups was not based on predefined criteria. Rather, the decision whether to treat with steroids was based on the individual health care provider's preference. It is not clear from these studies whether a positive outcome was simply the result of this selection bias or a even performance bias rather than a steroid effect, in which the more experienced caregivers were more inclined to use steroids (as well as other postoperative regimens including antibiotics or choleretic agents) given their expertise with the surgical and postoperative management of BA.

Case-control studies are particularly at risk for selection bias that may unduly weigh the outcome in favour of the exposure under evaluation. However in our review, the two case control studies (Vejchapipat et al [18] and Chung et al [23]), and one cohort study (Petersen et al [22], as well as the single RCT [28]), did not find a significantly favourable effect in either of the two measured outcomes between steroid and standard therapy groups.

Perhaps most importantly, there were significant discrepancies among the studies with regard to the treatment protocols including the steroid formulas used, the quantity and frequency of the doses delivered, and the routes of administration and duration of therapy. Each of these factors clearly contributes to the variation in results among different studies.

\section{CONCLUSION}

While the present meta-analysis found that steroids were ineffective for the improvement of KP outcome, we recognize the many limitations regarding the interpretation of our results, particularly given the challenges associated with the design of each of the steroid studies that have been published in the world medical literature. Our findings, however, do summarize and emphasize the current issues related to the difficulties associated with applying 'evidenced-based' decision making regarding the use of steroids for BA patients. At this time, no concrete recommendations based on published trials can be offered with respect to the use of steroids in the postoperative management of BA. We recognize that a large, randomized, prospective double-blind steroid trial using high-dose steroids is necessary to fully address the question of the effectiveness of steroids on the short- and intermediate-term post-KP outcomes for BA patients. We caution, however, that any future study should carefully address the many confounding factors cited in the present study so that eventually, a well planned study of sufficient size and comprehensive design will allow the opportunity to provide a definitive recommendation based on statistically interpretable and meaningful results. 
APPENDIX 1: QUALITY ASSESSMENT SHEET The Newcastle-Ottawa Scale for assessing the quality of nonrandomized studies in meta-analyses ${ }^{\dagger}$

\section{Case-control studies}

\begin{tabular}{lccc}
\hline Study & \multicolumn{2}{c}{ Selection Comparability Exposure } \\
\hline Meyers et al (12), 2003, USA & $* \star *$ & & $* *$ \\
Vejchapipat et al (18), 2007, Thailand & $* \star \star *$ & $*$ & $* *$ \\
Chung et al (23), 2008, Hong Kong & $* \star * *$ & $*$ & $* *$ \\
\hline
\end{tabular}

${ }^{\dagger}$ Grade A Low risk of bias (7-9 points); Grade B Moderate risk for bias (4-6 points); Grade $C$ High risk of bias (1-3 points); * = Points

\section{Cohort study ${ }^{\dagger}$}

\section{Study} Selection Comparability Outcome

Petersen et al (22), 2000, Germany

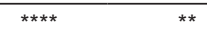

**

${ }^{\dagger}$ Grade A Low risk of bias (7-9 points); Grade B Moderate risk for bias (4-6 points); Grade C High risk of bias (1-3 points); * = Points

\section{The Jadad score for assessment of the quality of controlled trials methodology: Jadad score calculation}

Item Score

Was the study described as randomized (this includes words such as $1 / 1$ randomly, random, and randomization)?

Was the method used to generate the sequence of randomization $0 / 1$ described and appropriate (table of random numbers, computergenerated, etc)?

Was the study described as double blind?

Was the method of double blinding described and appropriate

(identical placebo, active placebo, dummy, etc)?

Was there a description of withdrawals and dropouts?

Deduct one point if the method used to generate the sequence of

randomization was described and it was inappropriate (patients were allocated alternately, or according to date of birth, hospital number, etc).

Deduct one point if the study was described as double blind but the $0 /-1$ method of blinding was inappropriate (eg, comparison of tablet versus injection with no double dummy).

The study scored 3 (out of a possible 5) because there was no description given for the details of the randomization and blinding

\section{REFERENCES}

1. Sokol RJ, Shepherd RW, Superina R, Bezzera J, Robuck P, Hoofnagle J. Screening and outcomes in biliary atresia: Summary of a National Institutes of Health Workshop. Hepatology 2007;46:566-581.

2. Sokol RJ, Mack C. Etiopathogenesis of biliary atresia. Semin Liver Dis 2001;21:517-24.

3. Chitsaz E, Schreiber R, Collet JP and Kaczorowski J. Biliary atresia: The timing needs a changin'. Can J Pub Health 2009;100:475-77.

4. Hartley JL, Davenport M, Kelly DA. Biliary atresia. Lancet 2009;14:1704-13.

5. Schreiber RA, Barker CC, Roberts EA, et al. Canadian Pediatric Hepatology Research Group. Biliary atresia: The Canadian experience. J Pediatr 2007;151:659-65.

6. Serinet $\mathrm{MO}$, Wildhaber BE, Broue P, et al. Impact of age at Kasai operation on its results in late childhood and adolescence: A rationale basis for biliary atresia screening. Pediatrics 2009; $123: 1280-6$

7. Schreiber RA, Barker CC, Roberts EA, Martin S. Biliary atresia in Canada: The effect of centre caseload experience on outcome. JPGN 2010;51:61-5.

8. Balisteri WF, Grand R, Hoofnagle J, et al. Biliary atresia; current concepts and research direction: Summary of a symposium. Hepatology 1996;23:1682-92.

9. Karrer FM, Lilly JE. Corticosteroid therapy in biliary atresia. J Pediatr Surg 1985;20:693-5.

10. Muraji T, Higashimoto Y. The improved outlook for biliary atresia with corticosteroid therapy. J Pediatr Surg 1997;32:1103-7.
11. Dillon PW, Owings E, Cilley R, Field D, Curnow A, Georgeson K. Immunosuppression as adjuvant therapy for biliary atresia. J Pediatr Surg 2001;36:80-5.

12. Meyers R, Book LS, O'Gorman MA, et al. High-dose steroids, ursodeoxycholic acid, and chronic intravenous antibiotics improve bile flow after Kasai procedure in infants with biliary atresia. J Pediatr Surg 2003;38:406-11.

13. Muraji T, Nio M, Ohhama Y, et al. Japanese Biliary Atresia Society. Postoperative corticosteroid therapy for bile drainage in biliary atresia - a nationwide survey. J Pediatr Surg 2004;39:1803-5.

14. Kobayashi H, Yamataka A, Koga H, et al. Optimum prednisolone usage in patients with biliary atresia postportoenterostomy. J Pediatr Surg 2005;40:327-33.

15. Tatekawa Y, Muraji T, Tsugawa C. Glucocorticoid receptor alpha expression in the intrahepatic biliary epithelium and adjuvant steroid therapy in infants with biliary atresia.

J Pediatr Surg 2005;40:1574-80.

16. Escobar MA, Jay CL, Brooks RM, et al. Effect of corticosteroid therapy on outcomes in biliary atresia after Kasai portoenterostomy. J Pediatr Surg 2006;41:99-103.

17. Shimadera S, Iwai N, Deguchi E, Kimura O, Fumino S, Ono S. The significance of steroid therapy after hepatoportoenterostomy in infants with biliary atresia. Eur J Pediatr Surg 2007;17:100-3.

18. Vejchapipat P, Passakonnirin R, Sookpotarom P, Chittmittrapap S, Poovorawan Y. High-dose steroids do not improve early outcome in biliary atresia. J Pediatr Surg 2007;42:2102-5.

19. Stringer MD, Davison SM, Rajwal SR, McClean P. Kasai portoenterostomy: 12-year experience with a novel adjuvant therapy regimen. J Pediatr Surg 2007;42:1324-8.

20. Foroutan H.R, Hosseini A.H. Dehghani S.M, et al. Peri-operative high-dose $\mathrm{v}$ post-operative low dose steroid therapy in the management of biliary atresia: A preliminary report. Iran J Med Sci 2008;33:79-83.

21. Shimadera S, Iwai N, Deguchi E, et al. Significance of ductal plate malformation in the postoperative clinical course of biliary atresia. J Pediatr Surg 2008;43:304-7.

22. Petersen C, Harder D, Melter M, et al. Postoperative high-dose steroids do not improve mid-term survival with native liver in biliary atresia. Am J Gastroenterol 2008;103:712-9.

23. Chung HY, Kak Yuen Wong K, Cheun Leung Lan L, Kwong Hang Tam P. Evaluation of a standardized protocol in the use of steroids after Kasai operation. Pediatr Surg Int 2008;24:1001-4.

24. Lao OB, Larison C, Garrison M, Healey PJ, Goldin AB. Steroid use after the Kasai procedure for biliary atresia. Am J Surg 2010;199:680-4.

25. Wells GA, Shea B, O'Connell D, et al. The Newcastle-Ottawa Scale (NOS) for assessing the quality of nonrandomized studies in metaanalyses. Department of Epidemiology and Community Medicine, University of Ottawa, Canada. <www.ohri.ca/programs/clinical_ epidemiology/oxford.asp> (Accessed on November 27, 2010).

26. Jadad AR, Moore RA, Carroll D, et al. Assessing the quality of reports of randomized clinical trials: Is blinding necessary? Control Clin Trials 1996;17:1-12.

27. DerSimonian R, Laird N. Meta-analysis in clinical trials. Control Clin Trials 1986; 7:177-88.

28. Davenport M, Stringer MD, Tizzard SA, McClean P, Mieli-Vergani G, Hadzic N. Randomized, double-blind, placebo-controlled trial of corticosteroids after Kasai portoenterostomy for biliary atresia. Hepatology 2007;46:1821-7.

29. Sutton AJ, Duval SJ, Tweedie RL, Abrams KR, Jones DR. Empirical assessment of effect of publication bias on meta-analyses. BMJ 2000;320:1574-7.

30. Kasai M, Suzuki S. [A new operation for "non-correctable" biliary atresia: Hepatic portoenterostomy.] Shujutsu 1959;13:733-9.

31. Rodeck B, Becker AC, Gratz KF, Petersen C. Early predictors of Success of Kasai operation in children with biliary atresia. Eur J Pediatr Surg 2007;17:308-12.

32. Shneider B, Brown MB, Haber B, et al. A multicenter study of the outcome of biliary atresia in the United States, 1997-2000. J Peds 2006;148:467-74.

33. Lilly JR, Karrer FM, Hall RJ, et al. The surgery of biliary atresia. Ann Surg 1989;210:289-94.

34. A randomized double-blinded, placebo controlled trial of corticosteroid therapy following portoenterostomy. $<$ http://clinicaltrials.gov/ct2/show/NCT00294684?term=biliary+atre sia+and+US\& rank=2> (Accessed on November 18, 2010). 


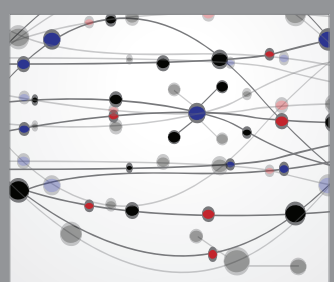

The Scientific World Journal
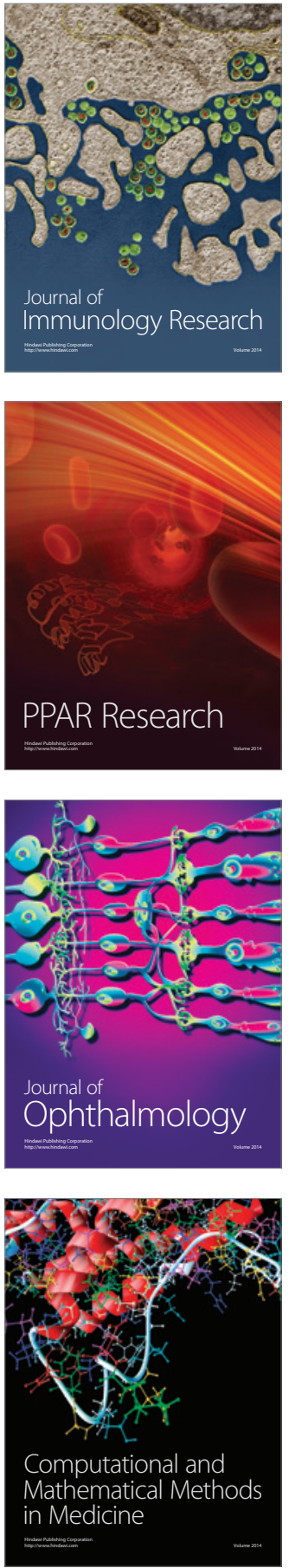

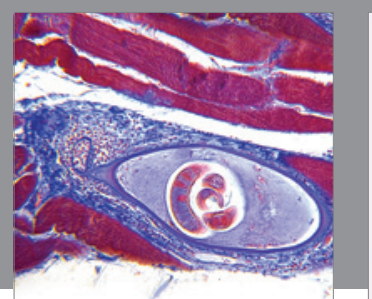

Gastroenterology Research and Practice

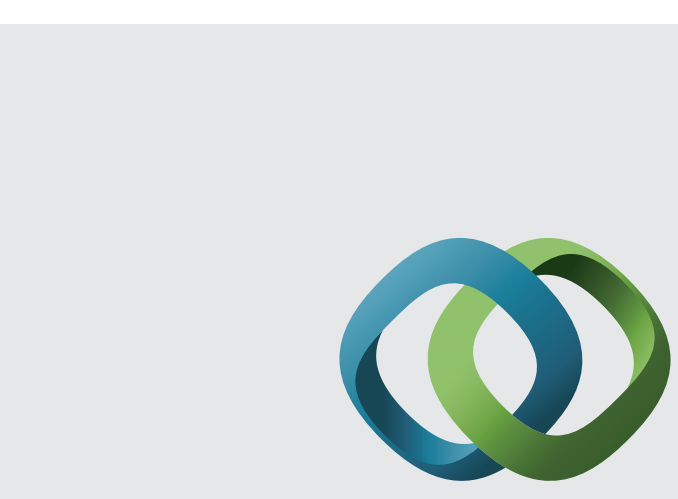

\section{Hindawi}

Submit your manuscripts at

http://www.hindawi.com
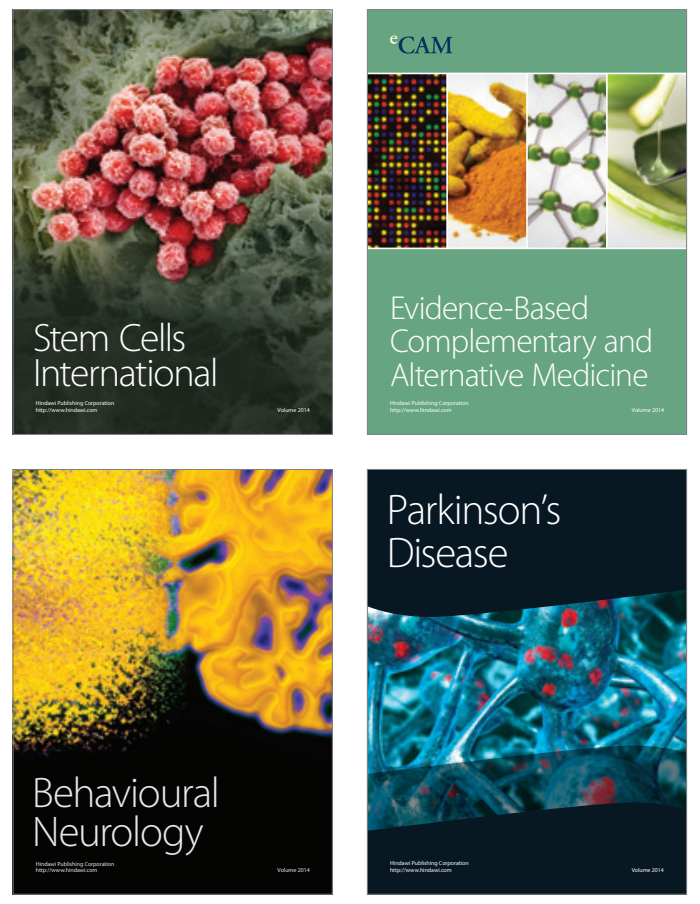
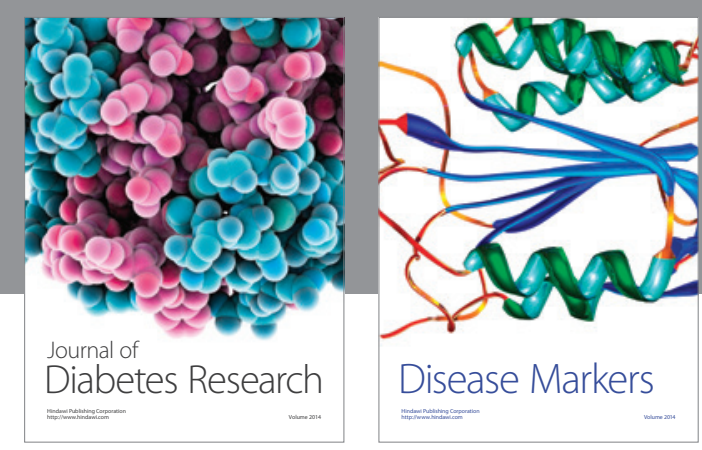

Disease Markers
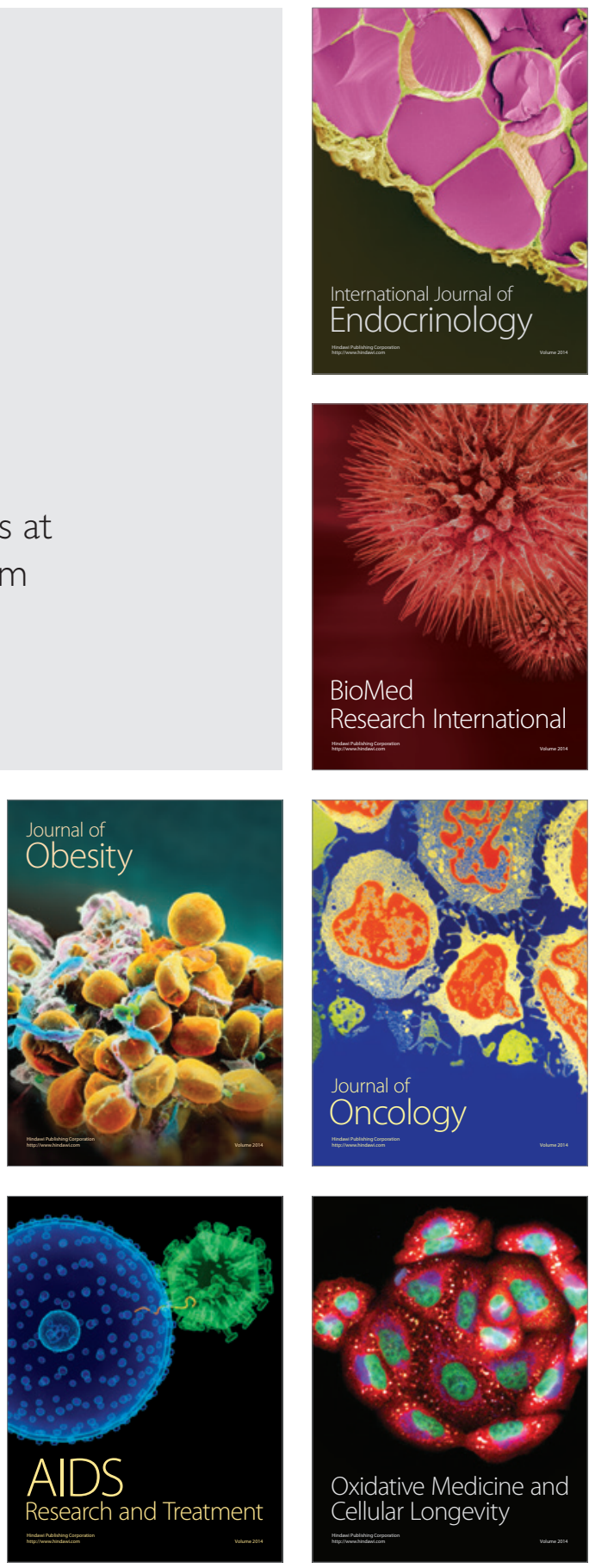